Original Research Paper

\title{
Hydrogen is a Friend, or an Enemy, of the Environment?
}

\author{
${ }^{1}$ Relly Victoria Virgil Petrescu, ${ }^{2}$ Raffaella Aversa, ${ }^{3}$ Taher M. Abu-Lebdeh, \\ ${ }^{2}$ Antonio Apicella and ${ }^{1}$ Florian Ion Tiberiu Petrescu \\ ${ }^{I}$ ARoTMM-IFToMM, Bucharest Polytechnic University, Bucharest, (CE), Romania \\ ${ }^{2}$ Advanced Material Lab, Department of Architecture and Industrial Design, \\ Second University of Naples, 81031 Aversa (CE), Italy \\ ${ }^{3}$ North Carolina A and T State University, USA
}

Article history

Received: 08-02-2018

Revised: $15-03-2018$

Accepted: 17-03-2018

Corresponding Author:

Florian Ion Tiberiu Petrescu

ARoTMM-IFToMM, Bucharest

Polytechnic University,

Bucharest, (CE), Romania

E-mail: fitpetrescu@gmail.com

scipub02@gmail.com

\begin{abstract}
Hydrogen is the best friend of man and the environment. Actually, it is the core element from that can extract energy, at infinity, in various forms. Until now has not been sufficiently exploited, but once with the evolution of the human species is the time to start to pool all types of energy which the hydrogen and its isotopes may donate them to us. Obviously the most abundant are nuclear energies which may be extracted from the hydrogen, either by well-known reaction of fission or through the much-desired fusion. In the reaction of a merger Deuterium-Tritium, for example, the energy required to overcome the Coulomb barrier is $0.1 \mathrm{MeV}$. Conversion between the energy and the temperature shows that the barrier of $0.1 \mathrm{MeV}$ would be exceeded at a temperature of over 1.2 billion Kelvin degrees. According to the static calculations required a temperature of fusion to warm temperature is about 4 billion degrees. There is already an increase of almost four times than the latest calculations indicated by specialists. But calculating using radius determined dynamically, when the energy required is much higher, we come to a temperature necessary for the attainment of the thermonuclear fusion reaction of 40 trillion degrees, as for any $1 \mathrm{keV}$ is needed about 10 million degrees temperature. Hot temperatures the merger being elusive, scientists have thought of achieving cold fusion.
\end{abstract}

Keywords: Energy, Annihilation Process, Matter, Antimatter, Hydrogen, Friendly Environmental, Sustainable Energy, Renewable Energy, Hydrogen Transport, Hydrogen Energy, Nuclear Energy, Fission, Nuclear Fusion, Annihilation Reaction, Isotopes, Ions

\section{Introduction}

Hydrogen is the chemical element of atomic number 1 , symbol $\mathrm{H}$. The hydrogen present on Earth consists almost entirely of the stable isotope ${ }^{1} \mathrm{H}$ (one proton, zero neutron), but contains about $0.01 \%$ of ${ }^{2} \mathrm{H}$ (one proton, one neutron), also stable. A third isotope ${ }^{3} \mathrm{H}$ (one proton, two neutrons), unstable, is produced in nuclear explosions. These three isotopes are respectively called Protium, Deuterium and Tritium.

Hydrogen can have the oxidation numbers 0 (dihydrogen $\mathrm{H}_{2}$ or metallic hydrogen), +1 (in most of its chemical compounds) and -1 (in metal hydrides). Hydrogen is an electropositive element, frequently ionized in the $\mathrm{H}^{+}$or $\mathrm{H}_{3} \mathrm{O}^{+}$state. But it also forms covalent bonds, especially in water and organic matter.
Hydrogen is the main constituent of the Sun and most of the stars (whose energy comes from the thermonuclear fusion of this hydrogen) and interstellar or intergalactic matter. It is a major component of giant planets, in metallic form at the heart of Jupiter and Saturn and in the form of solid, liquid or gaseous dihydrogen in their outermost layers and in other giant planets. On Earth it is mostly present in liquid, solid (ice) or gaseous (water vapor) water, but it is also in the form of dihydrogen $\mathrm{H}_{2}$ and methane $\mathrm{CH}_{4}$ in the fumes of certain volcanoes (Bonev et al., 2004).

This gas was brought to light by Cavendish in 1766 (Henry Cavendish, from Wikipedia), who called it "flammable air" because it burned or exploded in the presence of oxygen to form water vapor. Lavoisier has designated this gas by the name hydrogen, which is 
composed of the prefix «hydro», the Greek $\square \delta \omega \rho$ (hudôr) meaning «eau» and the suffix «gene», from the Greek $\gamma \varepsilon v v \square v$ (gennan), "generate». It is the gas of chemical formula $\mathrm{H}_{2}$ whose scientific name is now dihydrogen. In common parlance, dihydrogen is still commonly called "hydrogen" (Hydrogen, from Wikipedia; Simpson and Weiner, 1989).

Hydrogen is the most abundant element of the Universe: $75 \%$ by mass and $92 \%$ by number of atoms. It is present in large quantities in stars and gaseous planets; it is also the main component of nebulae and interstellar gas.

In the earth's crust, hydrogen represents only $0.22 \%$ of the atoms, far behind oxygen (47\%) and silicon $(27 \%)$. It is also rare in the terrestrial atmosphere, since the dihydrogen represents by volume only $0.55 \mathrm{ppm}$ of atmospheric gases. On Earth, the most common source of hydrogen is water, the molecule of which consists of two atoms of hydrogen and one atom of oxygen; Hydrogen is mainly the main component (in number of atoms) of any living matter associated with carbon in all organic compounds. For example, hydrogen represents $63 \%$ of the atoms and $10 \%$ of the mass of the human body (Simpson and Weiner, 1989).

Under very low pressures, such as those in space, hydrogen tends to exist in the form of individual atoms simply because it is then unlikely that they will collide to combine. The clouds of dihydrogen are at the base of the process of the formation of the stars.

Hydrogen is the simplest chemical element; its most common isotope consists only of a proton and an electron. Hydrogen is the lightest atom. Since it has only one electron, it can form only one covalent bond: it is a univalent atom.

However, the solid hydrogen can be metallic when it is under very high pressure. It then crystallizes with a metallic bond (see metallic hydrogen). In the periodic table of elements, it is found in the column of the alkali metals. However, being not present in this state on Earth, it is not considered a metal in chemistry.

The hydrogen capture cross section (200 mb to thermal neutrons and $0.04 \mathrm{mb}$ to fast neutrons) is sufficiently small to allow the use of water as moderator and refrigerant for nuclear reactors. A coolant for a reactor nuclear is a coolant in a nuclear reactor used to remove the heat from the reactor core nuclear material and transfer it to the electric power generators and environment. Frequently, a chain of two loops are used as the primary circuit cooling system takes over the radioactivity levels in the short term from the reactor. Almost all nuclear power plants which operate at present are reactors with water simple using water under high pressure as an agent of the cooling system and the moderator neutrons. About a third are reactors with boiling water in the case in which the staff member the primary cooling system suffers from the transitional period of the phase to steam in the inside of the reactor. Approximately $2 / 3$ are reactors with high-pressure water at a pressure and higher. The current reactors stay under the critical point at approximately $374{ }^{\circ} \mathrm{C}$ and 218 bar, where disappears the distinction between the fluid and gas, which limits the thermal efficiency, but the reactor with water supercritical proposed would operate above this point. Designs with heavy water use nitrous oxide Deuterium, which has properties similar to water", but much smaller capture neutrons, allowing the moderation was not performed. In the Table 1 one can see the nuclear reactor coolants (Nuclear reactor coolant, from Wikipedia).

The bars of fuel creates high temperatures that boils water then turns the water in the steam. During the disaster, when the power interruption of operation happen and generator of diesel power which ensures the supply of the urgency of the water pump is affected by the tsunami, earthquake, in the case where no fresh water is pumped to cool the bars of fuel, then the bars of fuel continues to heat up. After the bars of fuel reaches more than 1200 degrees Celsius, zirconium will interact with steam and divided the hydrogen from the water.

As the hydrogen can then be released from the reactor vessel and the insulation and, in the case where the hydrogen accumulates in sufficient quantities in a concentration of 4 percent or more in the air when that hydrogen can explode, as product seemingly at reactors at Fukushima Daiichi No. 1, 3, 4, but the reactor nr 2 Open the sunroof to release of gas of hydrogen radioactive, drop in pressure of hydrogen, but contaminated environment so that the reactor No. 2 does not exploded (Fig. 1).

Table 1: Nuclear reactor coolants

\begin{tabular}{lll}
\hline Coolant & Melting point & Boiling point \\
\hline Heavy water at 155 bar & & $345^{\circ} \mathrm{C}$ \\
NaK eutectic & $-11^{\circ} \mathrm{C}$ & $785^{\circ} \mathrm{C}$ \\
Sodium & $97.72^{\circ} \mathrm{C}$ & $883^{\circ} \mathrm{C}$ \\
FLiNaK & $454^{\circ} \mathrm{C}$ & $1570^{\circ} \mathrm{C}$ \\
FLiBe & $459^{\circ} \mathrm{C}$ & $1430^{\circ} \mathrm{C}$ \\
Lead & $327.46^{\circ} \mathrm{C}$ & $1749^{\circ} \mathrm{C}$ \\
Lead-bismuth eutectic & $123.5^{\circ} \mathrm{C}$ & $1670^{\circ} \mathrm{C}$ \\
\hline
\end{tabular}

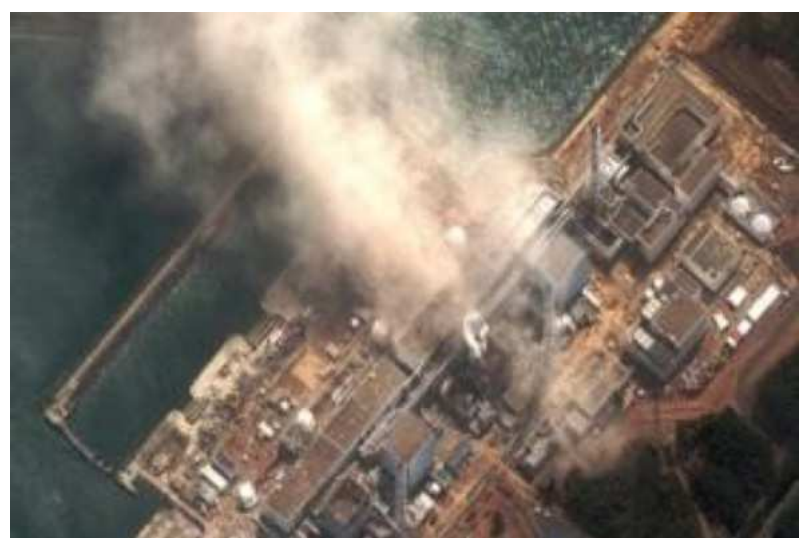

Fig. 1: The explosion in Fukushima of reactors No. 1, 3, 4 


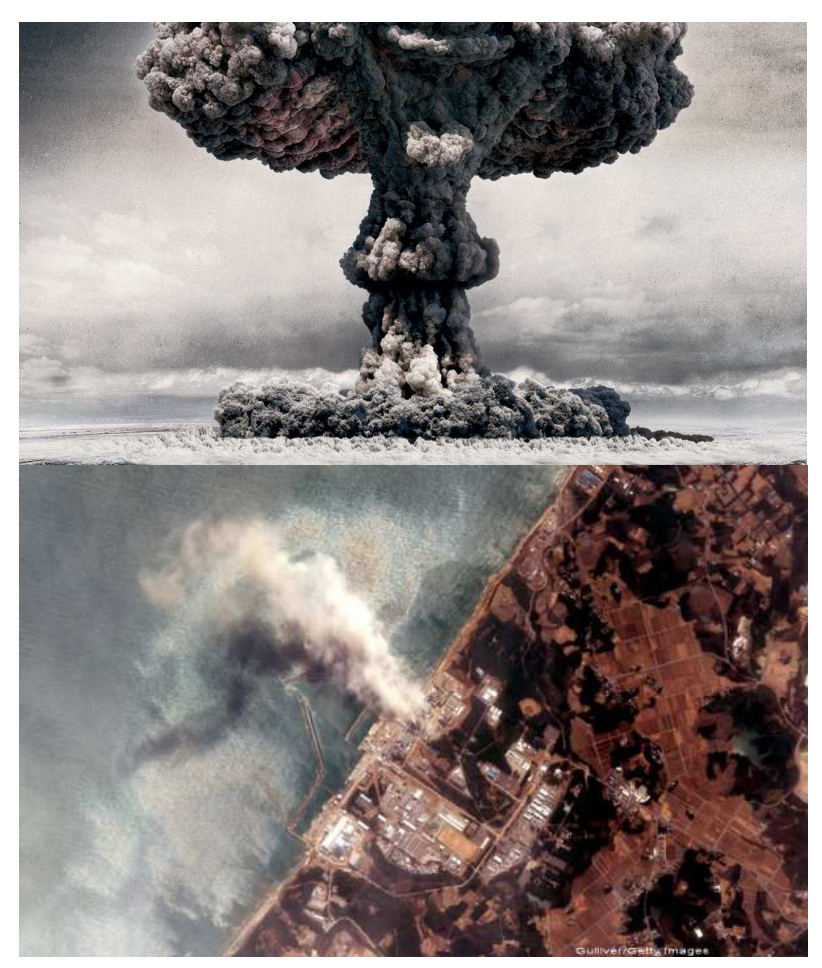

Fig. 2: Chernobyl nuclear explosion of 30 years ago (1986)

Here is the time for us to ponder least and to make a small comment. When we say that the energy donated by hydrogen is amiable, we are referring in general at her, but in particular to the nuclear fusion. Nuclear energy for fission has given us and many problems unpleasant over time. But still it has been and that who made us out from the energy crisis installed on the Earth, since years 19501970. Without nuclear energy for fission, mankind was collapse. It can be said that this energy, represented, to humanity, a big harm necessary. Want the images in Fig. 2 to remember us for a moment about the Chernobyl nuclear explosion of 30 years ago (1986).

The two disastrous events mentioned, have produced the environment some wounds hard to imagine or forgotten, wounds on very long term. For this reason, many governments, starting with the USA, UK, China, Germany, Canada, etc, have started to implement the massive alternative energies and in particular the solar central photovoltaic cells and wind turbines.

But let us go back now to the topic of the work, hydrogen.

The hydrogen atom is the simplest atom that exists. This is the one for which the resolution of the Schrödinger equation in quantum mechanics is the simplest (Schrödinger equation, from Wikipedia). The study of this case is fundamental, since it allowed to explain the atomic orbitals and then the different chemical bonds with the theory of the molecular orbitals.

Hydrogen is the only element of which each isotope bears a specific name, because their mass difference (compared to that of the hydrogen atom) is significant: single to double or triple, which explains why, unlike which applies to isotopes in general, these differences may influence the chemical properties of deuterium or tritium in relation to the Protium (isotopic effect). For example, heavy water $\left(\mathrm{D}_{2} \mathrm{O}\right)$ is toxic (at high doses) for many species: due to the large difference in mass between the isotopes, the kinetics of the reactions in "heavy" aqueous solution is considerably slowed down (Clayton, 2003; Petrescu et al., 2016a; 2016b).

The most notable isotopes of hydrogen are:

Light hydrogen or ${ }^{1} \mathrm{H}$ protium, the most abundant ( $99.98 \%$ of natural hydrogen). The nucleus is simply made of a proton and therefore does not have a neutron. It is a stable isotope (Petrescu and Calautit, 2016; Tikhonov and Volkov, 2002).

Deuterium ${ }^{2} \mathrm{H}$ (or D), much less abundant (from 0.0082 to $0.0184 \%$ of natural hydrogen, $0.015 \%$ on average). The nucleus consists of a proton and a neutron, it is also a stable isotope. On Earth it is mainly present in deuterated water HDO (semi-heavy water). Tritium ${ }^{3} \mathrm{H}$ (or T), present only in tiny amounts in natural hydrogen (one tritium atom per $10^{18}$ hydrogen atoms). The nucleus consists of a proton and two neutrons, is radioactive and is transformed into ${ }^{3} \mathrm{He}$ by emission of an electron ( $\beta^{-}$radioactivity). ${ }^{2} \mathrm{H}$ and ${ }^{3} \mathrm{H}$ can participate in nuclear fusion reactions.

The radiotoxicity of tritium is considered to be very low when present in HTO form (tritiated water), it is less known and less well understood when present in organic form (studies show contradictory or very variable results according to their protocols Experimental).

In the environment, tritium can take the place of the Protium in all molecules including hydrogen, including in biological molecules and even in DNA where it can cause DNA breakage, mutations or of cellular apoptosis. Since tritium is a rare isotope, its concentration in water and tissues is generally very low (excluding accidental contamination from an anthropogenic source of tritium).

Quadrium or tetradium ${ }^{4} \mathrm{H}$ (or Q), the most unstable isotope of hydrogen (its half-life is ultra-short: $1.39 \times 10^{-22}$ $\mathrm{sec})$. It decomposes by neutron emission.

Hydrogen $\left({ }^{7} \mathrm{H}\right)$, the neutron richest isotope ever observed. Its half-life is of the order of $10^{-21}$ seconds.

Hydrogen present in large quantities in the core of stars is a source of energy via nuclear fusion reactions, which combine 2 nuclei of hydrogen atoms ( 2 protons) to form a helium atom nucleus. The two paths of this natural nuclear fusion are the proton-proton chain of Eddington and the catalytic-carbon-nitrogen-oxygen cycle of Bethe and von Weizsäcker.

The nuclear fusion carried out in hydrogen bombs or $\mathrm{H}$ bombs concerns isotopes of the fusion (of hydrogen in helium) in progress in the stars: Heavy isotopes of hydrogen, helium 3 , tritium ... 
Indeed, in a H-bomb, the nuclear reactions last only a few tens of nanoseconds, which allows only reactions in a single step. Now, the transformation of hydrogen into helium takes place in several stages, of which the first (reaction of a proton) is extremely slow.

Except at extremely low pressures (as in intergalactic space) or extremely high (as in the central parts of Jupiter and Saturn), the simple hydrogen body is formed of molecules $\mathrm{H}_{2}$ (dihydrogen).

At these extremely high pressures, hydrogen is in a so-called "dark" state, intermediate between a gas and a metal. It does not reflect light and does not transmit it. It also becomes very weakly conductive of electricity (Okumura et al., 1990).

At the lowest pressures hydrogen is a monoatomic gas. At the highest pressures hydrogen becomes a metal (liquid or solid) similar to the alkali metals which follow it in group 1 of the Mendeleev table (Periodic table, from Wikipedia).

The dihydrogen molecule exists under two isomers of nuclear spin: hydrogen ortho (parallel spins) and hydrogen para (antiparallel spins).

\section{Nuclear Fission}

Fission is a nuclear reaction which has the effect of breaking the kernel in 2 (or more) fragments of the earth approximately equal, neutrons fast, radiation and thermal power.

The elements which fission with neutrons thermal, they are called fissile materials; ex.: ${ }^{233} \mathrm{U},{ }^{235} \mathrm{U},{ }^{239} \mathrm{Pn},{ }^{241} \mathrm{Pu}$. Items that fission fast neutrons are called fissionable materials and those that capture neutrons is transformed into fissile material, are considered fertile materials; Ex. ${ }^{232} \mathrm{Th},{ }^{238} \mathrm{U}$.

Ex. fissile 235U (see Equation 1):

$$
{ }_{0}^{1} n_{t h}+{ }_{92}^{235} U \rightarrow{ }_{92}^{236} U^{*} \rightarrow{ }_{56}^{144} \mathrm{Ba}+{ }_{36}^{89} \mathrm{Kr}+3{ }_{0}^{1} n_{\text {fast }}
$$

Fission energy is distributed, as kinetic energy of fission fragments, behaving like small particles go.

Neutrons resulting from fissions fall into two groups: prompt and delayed. They are released with the prompt fission fragments (FF) (even by $\mathrm{FF}$ after $10^{-14} \mathrm{~s}$ ) and energies of max. $6 \mathrm{MeV}, 0.85 \mathrm{MeV}$ energy is probable. Simultaneously $\gamma$ radiation is delivered promptly. Delayed neutrons are emitted as the nuclei dex excitement products arising from the disintegration of $\beta$ - FF.

Nuclear fission (known as nuclear fission) (Fig. 3), is a process in which an atom's nucleus breaks into two or more smaller nuclei, called fission products and, usually, a certain number of individual particles. Hence, fission is a form of elemental transmutation.

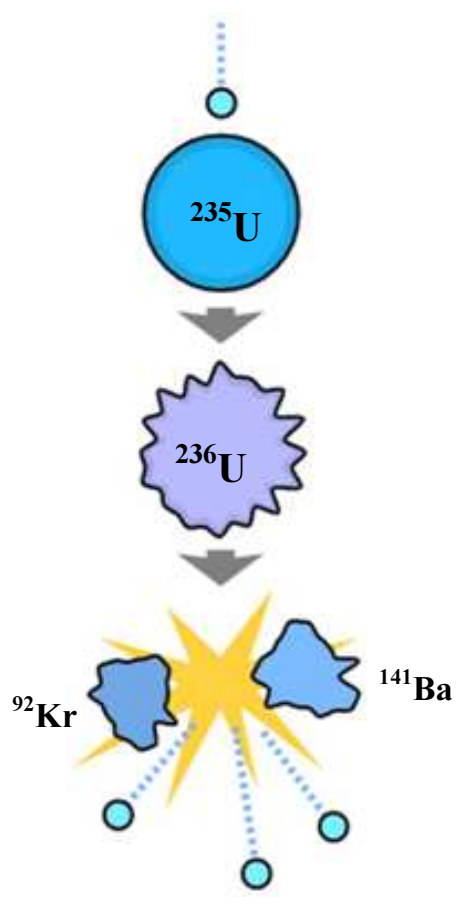

Fig. 3: Nuclear fission

The individual particles can be neutrons, photons (usually in the form of gamma rays) and other nuclear fragments such as beta particles and alpha particles. Fission of heavy elements is an exothermic reaction and can release substantial amounts of energy as gamma radiation and kinetic energy of the fragments (heating volume of material in which fission occurs).

Nuclear fission is used to produce energy in power plants and nuclear weapons explosions.

Fission is useful as a power source because some materials, called nuclear fuel, on the one hand generates neutrons as "players" of the fission process and, on the other hand, are initiating fission-impact (those exact) free neutrons.

Nuclear fuels may be used in the nuclear chain reaction self-maintained, which releases energy in controlled amounts in a nuclear reactor or uncontrolled amounts, quickly, in a nuclear weapon.

The amount of free energy contained in nuclear fuel is millions of times greater than the free energy contained in a similar mass of chemical fuel (gasoline, for example), this making nuclear fission a very tempting source of energy; however byproducts of nuclear fission are highly radioactive and can remain so even for thousands of years, having to deal with the important issue of nuclear waste.

Concerns about waste and the accumulation of huge destructive potential of nuclear weapons counterbalance the desirable qualities of fission as an energy source, which gives rise to intense political debate on the issue of nuclear power. 
To enriching nuclear fuel for fission is used and heavy water.

Also heavy water it is used and to cool the reaction of nuclear fission.

\section{Reaction of the Fusion When Warm (or Thermonuclear Fusion)}

Nuclear fusion is the process by which two atomic nuclei reacts to form a new kernel, more difficult (with weight higher than the initial kernels. As a result of the merger are produced and other particles subatomic particles such as neutrons or alpha-ray (cores of helium) or beta (electrons or positrons).

Because of the cores of the participating in the merger are loaded, the reaction of the fusion can take place only when the two cores have enough kinetic energy to overcome the electrical potential (reject diagram) and therefore is close enough so that the nuclear forces (which have a limited range) can rearrange nucleons. This condition involves the extremely high temperatures if the reaction takes place in a plasma or acceleration in the cores' accelerators the particle filter.

Nuclear fusion is the main source of energy in the stars active.

Nuclear fusion may be classified according to the conditions in the thermonuclear fusion and fusion to cold. The latter has the status of a controversial.

The investigation of the merger when cold is a domain active. Shall be investigated (in this respect) electrochemical systems with palladium and heavy water for triggering the merger deuterons.

Thermonuclear fusion could become a source of energy for virtually unlimited (eco-friendly and) when reactors merger (that at present are located in the experimental phase and do not produce a net surplus of energy) will become viable from a technological point of view and economically.

Thermonuclear fusion is a way to carry out the merger nuclear, through the use of extremely high temperatures. There are two forms of thermonuclear fusion uncontrolled:, in which energy is released in an uncontrolled manner, as it is in the arms of fusion, such as "bomb with hydrogen" and controlled in the case in which the reactions of merger took place in an environment that allows a certain of the energy to be evaluated for the purposes of construction.

The temperature is a measure of the kinetic energy average of the particulate sampling system, so that by heating the material will get energy. After it has reached a sufficient coolant temperature, the date of the criterion of Lawson, the energy consequences of plasma is enough to overcome the Coulomb barrier and particles may merge together.

In the reaction of a merger Deuterium-Tritium, for example, the energy required to overcome the Coulomb barrier is $0.1 \mathrm{MeV}$. Conversion between the energy and the temperature shows that the barrier of $0.1 \mathrm{MeV}$ would be exceeded at a temperature of over 1.2 billion Kelvin degrees.

In works (Petrescu, 2012; Petrescu and Calautit, 2016) it has been demonstrated that the required temperature of controlled thermonuclear fusion is in reality much higher, it exceeding 4 billion degrees.

For this reason the authors of the work suggests be transition to the reaction of the fusion from cold, times the insertion in the framework of the thermonuclear reaction (of the fusion) of certain elements (phases additional), which can force to start reaction.

To force the fusion reaction to start it is necessary to bomb the Deuterium particles with other Deuterium particles accelerated to an energy level able to merge two Deuterium particles (Petrescu, 2012).

First one should determine the necessary speed of the accelerated particles needed to start cold fusion when they will collide. It may use the original Equation 2 (Petrescu and Calautit, 2016; Petrescu et al., 2016).

This speed has the value: $\mathrm{v}=691664.8602[\mathrm{~m} / \mathrm{s}]$.

Second one could determine the radius $\mathrm{R}$ of a moving Deuterium particle, using the relationship 3.

Third one may calculate the potential energy of the two adjacent Deuterium particles on fusion (Halliday and Robert, 1966). This is the minimum translational kinetic energy that must reach a Deuterium particle accelerated to produce fusion by collision (using the form 4).

Hot temperatures the merger being elusive, scientists have thought of achieving cold fusion.

Today there are several methods proposed for the completion of the merger from cold.

The proposed method by the authors of the paper is the one already presented and in other articles published previously (Petrescu, 2012; Petrescu and Calautit, 2016; Petrescu et al., 2016).

Instead of waiting to produce an themselves fusion through higher temperatures, it propose to start the fusion reaction by colliding the Deuterium particles from the fusion recipient with other Deuterium ions accelerated in a circular (or linear) accelerator, up to the necessary energy, imposed by relation 4 .

The reactions of merger have already been presented in the works of the previous:

$$
\left\{\begin{array}{l}
x^{4}+a x^{3}+b x^{2}-c x+d=0 \\
a=2 c^{2} \\
b=\frac{c^{2}\left(q_{1} q_{2}\right)^{2}}{5 h^{2} \varepsilon_{0}^{2}} \\
c=\frac{2 c^{4}\left(q_{1} q_{2}\right)^{2}}{5 h^{2} \varepsilon_{0}^{2}} \\
d=\frac{c^{4}\left(q_{1} q_{2}\right)^{4}}{100 h^{4} \varepsilon_{0}^{4}}
\end{array}\right.
$$


$R=\sqrt{\frac{5}{4}} \cdot \frac{h \cdot \sqrt{c^{2}-v^{2}} \cdot \sqrt{c^{2}-\frac{v^{2}}{2}-c \cdot \sqrt{c^{2}-v^{2}}}}{\pi \cdot m_{0} \cdot c^{2} \cdot v}$

$E_{p}=\frac{q_{1} \cdot q_{2}}{8 \pi \cdot \varepsilon_{0} \cdot R}$

With $\mathrm{m}_{0}$ deuteron $=3.34524 \mathrm{E}-27[\mathrm{~kg}]$ and $\mathrm{v}=$ $691664.8602[\mathrm{~m} / \mathrm{s}]$, the radius of one Deuteron at this velocity (calculated with 3 ) takes the below value:

$$
R_{D d}=1.91788 E-19[\mathrm{~m}](\text { dynamic at } v=0.002307088 c)
$$

Static (with classical calculations) RDs $=1.827 \mathrm{E}-$ $15[\mathrm{~m}]$.

Potential energy has the below value (for a dynamic radius, in movement):

$$
\begin{aligned}
& U=E p=6.01333 E-10[\mathrm{~J}]=3753521838[\mathrm{eV}] \\
& =3753521.838[\mathrm{KeV}]=3753.521838[\mathrm{MeV}] \\
& =3.753521838[\mathrm{GeV}]
\end{aligned}
$$

Potential energy has the below value (for a static radius), (Petrescu, 2012):

$$
\begin{aligned}
& U=E p=6.31 E-14[\mathrm{~J}]=3.94 E 05[\mathrm{eV}] \\
& =394[\mathrm{KeV}]
\end{aligned}
$$

This means that according to the static calculations required temperature of fusion to warm temperature is about 4 billion degrees (Petrescu, 2012). There is already an increase of almost four times than the latest calculations indicated by specialists.

But calculating using radius determined dynamically, when the energy required is much higher, we come to a temperature necessary for the attainment of the thermonuclear fusion reaction of 40 trillion degrees, as for any $1 \mathrm{keV}$ is needed about 10 million degrees temperature (Petrescu and Calautit, 2016).

\section{Discussion}

Nuclear fusion reactions are performed using a single type of fuel, namely deuterium.

Hydrogen can be extracted in huge quantities from the waters of seas and oceans; the result immediately the advantage of a fuel, cheap, sustainable and friendly with the environment.

In addition we obtain energy through nuclear reaction and a friendly, inert gas, helium. No pollution, no imminent danger of an explosion.

Usually longer and uses lithium as an additive that can increase effectiveness reactions, but he is a friendly, cheap and abundant element.
Hot temperatures the merger being elusive, scientists have thought of achieving cold fusion.

In the reaction of a merger Deuterium-Tritium, for example, the energy required to overcome the Coulomb barrier is $0.1 \mathrm{MeV}$. Conversion between the energy and the temperature shows that the barrier of $0.1 \mathrm{MeV}$ would be exceeded at a temperature of over 1.2 billion Kelvin degrees (Thermonuclear fusion, from Wikipedia). According to the static calculations required temperature of fusion to warm temperature is about 4 billion degrees (Petrescu, 2012). There is already an increase of almost four times than the latest calculations indicated by specialists.

But calculating using radius determined dynamically, when the energy required is much higher, we come to a temperature necessary for the attainment of the thermonuclear fusion reaction of 40 trillion degrees, as for any $1 \mathrm{keV}$ is needed about 10 million degrees temperature (Petrescu and Calautit, 2016).

Hot temperatures the merger being elusive, scientists have thought of achieving cold fusion.

The proposed method by the authors of the paper is the one already presented and in other articles published previously (Petrescu, 2012; Petrescu and Calautit, 2016; Petrescu et al., 2016). Instead of waiting to produce an themselves fusion through higher temperatures, it propose to start the fusion reaction by colliding the Deuterium particles from the fusion recipient with other Deuterium ions accelerated in a circular (or linear) accelerator, up to the necessary energy, imposed by relation 4 (Petrescu and Calautit, 2016a; 2016b; Petrescu, 2011, 2012a; 2012b; 2014; 2015; Petrescu and Petrescu, 2011; 2012; 2014; Petrescu et al., 2017a; 2017b; 2017c; 2017d; 2017f; 2016a; 2016b; 2016c; 2016d; Aversa et al., 2017a; 2017b; 2017c; 2016a; 2016b; 2016c; 2016d).

\section{Conclusion}

Mankind was saved from a huge crisis by introducing nuclear fission, but also, because of nuclear fission energy, there have been environmental large disasters.

Fusion energy promises many advantages, including the environment, but it's still not done.

As a temporary measure, now, it is necessary to introduce large amounts of wind and solar energy sources for a long time.

This way we avoid a new energy crisis and social, as well as new dangers for the environment.

The basic raw material needed to obtain new energies is the hydrogen. Used correctly it is the closest friend of man, but otherwise would become a fearsome foe.

\section{Acknowledgment}

This text was acknowledged and appreciated by Professor Guanying Chen Harbin Institute of Technology 
and SUNY Buffalo China and Shweta Agarwala Senior Research Scientist at Singapore Center for 3D Printing Nanyang Technological University Singapore, whom we thanks and in this way.

\section{Funding Information}

Petrescu F.I., 2012, Cold nuclear fusion. Plasma Physics And Fusion Technology (S70), INIS 44(16).

These matters are copyrighted. Copyright: Obtaining Energy by the Annihilation of the Matter with Antimatter - The Battle for Energy: nr. 1068 from 13.03.2011 [GfE qpGDzeh].

\section{Author's Contributions}

All the authors contributed equally to prepare, develop and carry out this manuscript.

\section{Ethics}

This article is original. Authors declare that are not ethical issues that may arise after the publication of this manuscript.

\section{References}

Aversa, R., D. Parcesepe, R.V. Petrescu, F. Berto and G. Chen et al., 2017b. Processability of bulk metallic glasses. Am. J. Applied Sci., 14: 294-301. DOI: 10.3844/ajassp.2017.294.301

Aversa, R., D. Parcesepe, R.V. Petrescu, G. Chen and F.I.T. Petrescu et al., 2016a. Glassy amorphous metal injection molded induced morphological defects. Am. J. Applied Sci., 13: 1476-1482. DOI: 10.3844/ajassp.2016.1476.1482

Aversa, R., F. Tamburrino, R.V. Petrescu, F.I.T. Petrescu and M. Artur et al., 2016c. Biomechanically inspired shape memory effect machines driven by muscle like acting NiTi alloys. Am. J. Applied Sci., 13: 1264-1271. DOI: 10.3844/ajassp.2016.1264.1271

Aversa, R., F.I.T. Petrescu, R.V. Petrescu and A. Apicella, 2016b. Biomimetic finite element analysis bone modeling for customized hybrid biological prostheses development. Am. J. Applied Sci., 13: 1060-1067. DOI: 10.3844/ajassp.2016.1060.1067

Aversa, R., R.V. Petrescu, F.I.T. Petrescu and A. Apicella, 2017c. Nano-diamond hybrid materials for structural biomedical application. Am. J. Biochem. Biotechnol., 13: 34-41. DOI: 10.3844/ajbbsp.2017.34.41

Aversa, R., R.V. Petrescu, F.I.T. Petrescu and A. Apicella, 2016d. Smart-factory: Optimization and process control of composite centrifuged pipes. Am. J. Applied Sci., 13: 1330-1341.

DOI: 10.3844/ajassp.2016.1330.1341
Aversa, R., R.V. Petrescu, A. Apicella, S. Kozaitis and M.M. Mirsayar et al., 2017a. Triton for nuclear fusion. Am. J. Eng. Applied Sci., 10: 992-1000. DOI: 10.3844/ajeassp.2017.992.1000

Bonev, S.A., E. Schwegler, T. Ogitsu and G. Galli, 2004. A quantum fluid of metallic hydrogen suggested by first-principles calculations. Nature, 431: 669-672. DOI: 10.1038 /nature 02968

Clayton, D.D., 2003. Handbook of Isotopes in the Cosmos: Hydrogen to Gallium. 1st Edn., Cambridge University Press, ISBN-10: 0521530830, pp: 314.

Halliday, D. and R. Robert, 1966. Physics, Part II. 1st Edn., John Wiley and Sons, Inc., New York.

Henry Cavendish, from Wikipedia, the free encyclopedia.

Hydrogen, from Wikipedia, the free encyclopedia.

Nuclear reactor coolant, from Wikipedia, the free encyclopedia.

Okumura, A.M., L.I. Yeh, J.D. Myers and Y.T. Lee, 1990. Infrared spectra of the solvated hydronium ion: Vibrational predissociation spectroscopy of mass-selected $\mathrm{H} 3 \mathrm{O}+\bullet(\mathrm{H} 2 \mathrm{O}) \mathrm{n} \bullet(\mathrm{H} 2) \mathrm{m}^{\prime \prime}$ J. Phys. Chem., 94: 3416-3427.

Periodic Table, from Wikipedia, the free encyclopedia.

Petrescu F.I.T., 2012a. Cold nuclear fusion. Plasma Phys. Fusion Technol. (S70), INIS.

Petrescu, F.I., 2012. Cold nuclear fusion. Plasma Phys. Fusion Technol. (S70), INIS.

Petrescu, F.I.T. and J.K. Calautit, 2016a. About nano fusion and dynamic fusion. Am. J. Applied Sci., 13: 261-266 DOI: 10.3844/ajassp.2016.261.266

Petrescu, F.I.T. and J.K. Calautit, 2016b. About the light dimensions. Am. J. Applied Sci., 13: 321-325. DOI: 10.3844/ajassp.2016.321.325

Petrescu, F.I.T. and R.V. Petrescu, 2011. Perspective Energetice Globale. 1st Edn., Create Space Publisher, USA, ISBN-10: 978-1-4681-3082-9, pp: 80.

Petrescu, F.I.T. and R.V. Petrescu, 2014. Nuclear green energy. IJAP, 10: 3-14.

Petrescu, F.I.T. and R.V. Petrescu, 2012. News in Physics. 1st Edn., Books on Demand, ISBN-13: 978-3848229642, pp: 82.

Petrescu, F.I.T., 2011. Some New Elements in Physics. 1st Edn., Create Space Publisher, USA, ISBN-10: 978-1-4679-4880-7, pp: 72.

Petrescu, F.I.T., 2012b. Teoria Mecanismelor Color: Curs si Aplicatii. 1st Edn., CreateSpace Publisher, pp: 284.

Petrescu, F.I.T., 2014. Nuclear Fusion. Infinite Energy, 20: 44-47.

Petrescu, F.I.T., 2015. Improving medical imaging and blood flow measurement by using a new doppler effect relationship. Am. J. Eng. Applied Sci., 8: 582-588. DOI: 10.3844/ajeassp.2015.582.588

Petrescu, F.I.T., A. Apicella, A. Raffaella, R.V. Petrescu and J.K. Calautit et al., 2016c. Something about the mechanical moment of inertia. Am. J. Applied Sci., 13: 1085-1090. DOI: 10.3844/ajassp.2016.1085.1090 
Petrescu, F.I.T., A. Apicella, R.V. Petrescu, S.P. Kozaitis and R.B. Bucinell et al., 2016b. Environmental protection through nuclear energy. Am. J. Applied Sci., 13: 941-946. DOI: 10.3844/ajassp.2016.941.946

Petrescu, R.V., F.I.T. Petrescu, R. Aversa and A. Apicella, 2017f. Nano energy. Engevista, 19: 267-292. DOI: 10.22409/engevista.v19i2.760

Petrescu, R.V., R. Aversa, A. Apicella and F.I.T. Petrescu, 2017e. Proposed solutions to achieve nuclear fusion. Engevista, 19: 1496-1507. DOI: $10.22409 /$ engevista.v19i5.968

Petrescu, R.V., R. Aversa, A. Apicella, S. Li and G. Chen et al., 2016d. Something about electron dimension. Am. J. Applied Sci., 13: 1272-1276. DOI: 10.3844/ajassp.2016.1272.1276

Petrescu, R.V., R. Aversa, S.P. Kozaitis, A. Apicella and F.I.T. Petrescu, 2017b. Deuteron dimensions. Am. J. Eng. Applied Sc., 10: 649-654. DOI: 10.3844/ajeassp.2017.649.654

Petrescu, R.V., R. Aversa, S.P. Kozaitis, A. Apicella and F.I.T. Petrescu, 2017c. Some proposed solutions to achieve nuclear fusion. Am. J. Eng. Applied Sci., 10: 703-708. DOI: 10.3844/ajeassp.2017.703.708
Petrescu, R.V., R. Aversa, S.P. Kozaitis, A. Apicella and F.I.T. Petrescu, 2017d. Some basic reactions in nuclear fusion. Am. J. Eng. Applied Sci., 10: 709716. DOI: 10.3844/ajeassp.2017.709.716

Petrescu, R.V., R. Aversa, S. Li, M.M. Mirsayar and R. Bucinell et al., 2017a. Electron dimensions. Am. J. Eng. Applied Sci., 10: 584-602. DOI: 10.3844/ajeassp.2017.584.602

Petrescu, R.V.V., R. Aversa, A. Apicella, F. Berto and $\mathrm{S}$. Li et al., 2016a. Ecosphere protection through green energy. Am. J. Applied Sci., 13: 1027-1032. DOI: 10.3844/ajassp.2016.1027.1032

Schrödinger Equation, from Wikipedia, the free encyclopedia.

Simpson, J.A. and E.S.C. Weiner, 1989. "Hydrogen". Oxford English Dictionary. 2nd Edn., Clarendon Press, ISBN-10: 0-19-861219-2.

Thermonuclear fusion, from Wikipedia, the free encyclopedia.

Tikhonov, V. I. and A. A. Volkov, 2002. Separation of water into its ortho and para isomers. Science, 296: 23-63. 